Open Access

\title{
The geography of agriculture participation and food security in a small and a medium- sized city in Ghana
}

\author{
Hayford Mensah Ayerakwa ${ }^{1 *}$, Fred Mawunyo Dzanku ${ }^{2}$ and Daniel Bruce Sarpong ${ }^{3}$
}

* Correspondence: hayerakwa@ug.
edu.gh; ayerakwa@gmail.com
${ }^{1}$ University of Ghana Learning
Centres, School of Continuing and
Distance Education, University of
Ghana, Accra, Ghana
Full list of author information is
available at the end of the article

available at the end of the article

\begin{abstract}
The debate about the contribution of urban agriculture to urban household food security has not considered the possible differential effects by geography of production activities, focusing either on urban household's participation in agriculture irrespective of where the activity takes place, or restricting participation to production within urban and peri-urban areas, or more narrowly, production within build-up urban spaces. Using a sample of 2004 households in a small and a medium-sized city in Ghana, this article contributes by disentangling urban household's participation in agriculture by geography of production activities and the implications for the food security of urban households. We find no evidence from our sample that participation in agriculture in general matters for the food security of urban households. However, urbanites who produced food in both urban and rural areas had better food security in the medium-sized city.

Keywords: Urban agriculture, Food production, Food security, Techiman, Tamale, Ghana
\end{abstract}

\section{Introduction}

Several benefits of urban agriculture (UA) have been mentioned in the literature, including ecosystem services provisioning, social values, and health benefits (Clinton et al. 2018; Weidner et al. 2019). In this article, however, we focus on the contribution of UA to urban household food security (FS). UA has received considerable attention over the last decade for its actual and potential contribution to reducing food insecurity and poverty among urban households (Gerstl et al. 2002; Rogerson 2003; Mougeot 2005; Shifa and Borel-Saladin 2019). UA has been promoted by some civil society organizations, researchers, government agencies, and development agencies as a pro-poor initiative in developing countries (Mougeot 2006; Lee-Smith 2010; Clinton et al. 2018). Proponents argue that UA is an important source of food in most developing countries and is a critical food and nutrition security strategy among the urban poor (Armar-Klemesu 2000; Mougeot 2000; Nugent 2000; Maxwell 2001).

(c) The Author(s). 2020 Open Access This article is licensed under a Creative Commons Attribution 4.0 International License, which permits use, sharing, adaptation, distribution and reproduction in any medium or format, as long as you give appropriate credit to the original author(s) and the source, provide a link to the Creative Commons licence, and indicate if changes were made. The images or other third party material in this article are included in the article's Creative Commons licence, unless indicated otherwise in a credit line to the material. If material is not included in the article's Creative Commons licence and your intended use is not permitted by statutory regulation or exceeds the permitted use, you will need to obtain permission directly from the copyright holder. To view a copy of this licence, visit http://creativecommons.org/licenses/by/4.0/. 
The above notwithstanding, there is a continuing debate about the actual contribution of UA to urban food supply as a whole and to the food and nutrition security of participating urbanites in particular. Many authors (Ellis and Sumberg 1998; Zezza and Tasciotti 2010; Crush et al. 2011; Lee-Smith 2013; Stewart et al. 2013; Frayne et al. 2014) argue that the importance of UA for urban household FS has been overstated. For example, using nationally representative data for 15 countries including four from Africa, Zezza and Tasciotti (2010) found a positive association between participation in UA and FS in two of the African countries (Ghana and Nigeria) included in their sample. However, they cautioned that the positive relationship should not be overstated because of the minimal contribution of UA to the income of participating households; Ellis and Sumberg (1998) provided similar caution. Based on results of their study of 19 countries (including six from Africa), Badami and Ramankutty (2015) are even more doubtful about the contribution of UA to FS. They conclude as follows: "UA can only make a limited contribution to urban FS, let alone FS generally, in low-income countries" (p. 14).

As could be expected how UA is defined and measured matters for the conclusions one might reach, both with respect to the magnitude of participation and the association between UA and FS (Warren et al. 2015). The three most common definitions of UA in the literature are (a) crop and livestock production by urbanites irrespective of where the activity takes place (e.g., Zezza and Tasciotti 2010), (b) crop and livestock production within urban and peri-urban spaces irrespective of who is involved (e.g., Lee-Smith 2010), and (c) the growing of crops in cities (e.g., Clinton et al. 2018). Some authors (e.g., Badami and Ramankutty 2015) define UA more narrowly as primary vegetable production in "built-up" urban areas. Clearly, the association between UA and FS would depend on which of these definitions is applied. As an empirical point of departure from the received literature, the present article applies the first definition of UA mutatis mutandis as explained below.

Policies and institutions play a role in either promoting or inhibiting UA and its poverty and food insecurity reducing potential (Bryld 2003; Smit 2016). In Ghana for example, one of the six components of the Medium Term Agriculture Development Plan for the period 2011-2015 (METASIP I) was termed "Support to Urban and Peri-Urban Agriculture" (MoFA 2010). The program acknowledged urban and peri-urban agriculture as major contributors to national FS. Thus, the government of Ghana, unlike their counterparts in most African countries, viewed UA as important for FS and therefore sorts to promote it through an agricultural policy. However, it must be noted that the policy did not consider the interplay between agricultural production by urbanites in urban and rural spaces and urban household FS. In this sense, the policy did not contextualize UA in small and medium-sized cities (Ayerakwa 2017). It is worth noting that when the METASIP was revised in 2014, leading to the formulation of the METASIP II for the period 2014-2017, UA was mentioned only once in the entire policy document and was in relation to food safety, not an advocacy for promoting UA. This probably reflects a change in policy emphasis as pressure on urban lands continues to rise. 
It can be argued that the main concern of policy makers, practitioners, and urbanites within the context of increasing urbanization and rising urban poverty in Africa should be how UA as a livelihood activity contributes to poverty and food insecurity reduction rather than where the activity takes place per se. At the same time, however, the availability of land-the most important resource required for UA in Africa-could depend on proximity to peri-urban and rural areas. Yet, as observed by Abu Hatab et al. (2019b), the available UA literature has neglected interactions between urban and rural areas in urban food systems. For example, the UA literature has not considered the differential FS outcomes of food production by urbanites beyond urban and peri-urban boundaries.

Another important research issue that remains unaddressed, which is directly related to the gap identified in the UA literature by Abu Hatab et al. (2019b), is whether the opportunity for agricultural production by urbanites in both urban and rural areas matter for the FS of urban households. Living in an urban area and yet producing food in rural areas could be an important way of overcoming the land constraint to agricultural production within built-up urban areas.

Another gap in the literature relates to the paucity of knowledge on UA and FS in rapidly urbanizing secondary cities, which is partly due to the overconcentration of UA research on primary cities-Accra and Kumasi in the case of Ghana-although secondary cities tend to face the most pressing challenges and vulnerabilities to poverty and food insecurity (Battersby and Watson 2019). Zezza and Tasciotti (2010) also called for detailed and rigorous country-specific case studies to aid understanding of the precise magnitude and effects of UA.

Based on the gaps in the literature outlined above, the main objective of this article is to examine urban households' participation in agricultural production in both urban and rural areas and the implications for urban household FS. Addressing this objective contributes to the UA and FS literature in two major ways: first, by examining the household FS implications of food production by urbanites in both urban and rural areas rather than focusing on production in either urban or peri-urban spaces and second, we contribute by breaking away from the "large city" bias to provide evidence from the perspective of a small and a medium-sized city.

By employing statistically representative samples of households in two of Ghana's fastest growing urban areas-rather than a sample of UA participants as most studies have done (Poulsen et al. 2015) - we provide further and better understanding of the association between the geography of urban households' food provisioning arrangements and their FS. This approach is more relevant for unraveling important policy implications for UA, FS, and urban planning in general. The relevance of our approach could also be viewed within the context of increasing urbanization, which is associated with rising urban land values and thus makes the opportunity cost of putting such lands under agriculture prohibitively high. Such opportunity cost could be moderated by proximity to rural areas where pressure on land is lower, which is 
why it is important to differentiate between the FS effects of urban households' engagement in agriculture in urban areas on the one hand and rural areas on the other.

The rest of the paper is structured as follows. The next section describes the methodology by first providing a contextual background that informed the sampling strategy within the cities. The "Methodology" section also provides and analytical framework, describes the key variables employed, and presents the empirical econometric models. The results from the analyses are presented and discussed in the fourth section; the final section concludes.

\section{Methodology}

\section{The cities and sampling}

The data for this study comes from the Ghana component of the African Urban Agriculture Project. Techiman (in the Bono East regional capital) and Tamale (in the Northern regional capital) ${ }^{1}$ were purposively selected to break away from the large city bias that has characterized UA research in Ghana and other African countries. Table 1 presents selected characteristics of the two cities based on the most current census data that was collected in 2010 (Ghana Statistical Service 2014b; 2014a). We classified the cities as small and medium based on their relative population sizes. Whereas Techiman is classified as a municipal assembly, Tamale is classified as a metropolitan assembly. According to the 2010 census, the population of the Techiman Municipality was 147, 788 , but only about $64 \%$ lived in urban localities. Thus, the population of Techiman "city" was about 95,323 . On the other hand, about $81 \%$ of the 233,252 inhabitants of the Tamale Metropolis lived in urban localities, meaning that the population of Tamale "city" was about 188,468 . The population density is higher in Tamale than Techiman (Table 1).

To address the objective of this article, we carried out a survey that aimed at a representative random sample of households in each city. Based on the estimates in Table 1, the population of households at the time of the survey was 25,404 and 31,257 for Techiman and Tamale, respectively. According to Yamane (1967), the minimum sample size based on a random draw in this case can be determined by:

$$
n=\frac{\mathrm{N}}{1+\mathrm{N}\left(e^{2}\right)}
$$

where $n$ is the sample size, $N$ is the population of interest (i.e., number of households), and $e$ is the margin of error. With $5 \%$ margin of error (i.e., $e=0.05$ ), we needed a minimum of 400 households in each city. However, in order to increase the reliability of our results with higher precision and given that the sample frame was old (based on the 2010 population census), we randomly sampled 1000 households from each city. In addition to increasing the reliability and precision of our estimates, a larger sample provides adequate data that allows for the kind of rigorous statistical analysis that is

${ }^{1}$ At the time of the survey in 2013, Ghana was divided into 10 administrative regions. Techiman was located in the Brong-Ahafo Region while Tamale was in the Northern Region. In 2019, some of the 10 regions were sub-divided. The Bono East Region was carved out of the Brong-Ahafo Region, with Techiman as the new regional capital-a testament to its rapid growth.

${ }^{2}$ https://www.afsun.org/ 
Table 1 Selected characteristics of the two cities

\begin{tabular}{lll}
\hline Indicators & Urban Techiman & Urban Tamale \\
\hline 2010 census population & 95,323 & 188,468 \\
Estimated annual population growth rate (\%) & 2.6 & 2.2 \\
Population density (persons per $\mathrm{km}^{2}$ ) & 227.7 & 360.6 \\
Number of households & 23,566 & 29,322 \\
Mean household size & 4.0 & 6.3 \\
Percent of households engaged in agriculture & 33.0 & 26.1 \\
\hline
\end{tabular}

Source: Ghana Statistical Service (2014a and 2014b)

lacking in most of the UA literature as pointed out in a recent systematic review by Abu Hatab et al. (2019b).

The survey questionnaire was based on that developed by African Food Security Urban Network (AFSUN). ${ }^{2}$ The questionnaire captured information on household structure, housing characteristics, household cash income from all sources, household food access, dietary diversity, months of adequate food provisioning, food price changes, food sources, agricultural activities, food transfers, and food aid. The household survey data was complemented by qualitative interviews in August 2015 with opinion leaders in the two cities. In all, we conducted 11 and 10 key informant interviews in Techiman and Tamale, respectively. The reason for the qualitative interviews was to provide additional insights into institutional arrangements governing ownership and use of land in the two cities, and implications for urban food security, if any. It also provided the opportunity to seek contextual explanations for key findings from the survey. The qualitative interviews focused on motivations for engagement in agriculture, access to land for UA, and the general land holding arrangements in the cities.

\section{Analytical framework and key indicators}

Food security (FS) is a multidimensional phenomenon, which has four arms or pillars, namely food availability, access, utilization, and stability (FAO 2009). This article essentially focuses on the availability and access dimensions of FS. At the household level, FS can be achieved through at least three pathways: own production, food markets, and food transfers (Dzanku 2019). Conceptually, we can represent FS as a function of these pathways as:

$$
F S=f(\text { own_production, market, food_transfer }) .
$$

This means that own food production may not be necessary for the attainment of FS among urban households in particular. Urbanites could allocate household resources towards activities that yield the highest return, subject to factor market constrains, and then use the income gained from such activities to purchase food thus achieving FS via the food market arm. Analytically therefore, the question of whether or not urbanites who are engaged in food production have better FS than those who do not engage in the activity is undetermined, and the answer must be found in specific empirical contexts. 
The outcome variable of interest in this article is a measure of household FS. Following Coates et al. (2007), we use the Household Food Insecurity Access Scale (HFIAS) to classify households as food secure or not based on a set of nine questions. The questions take into account a reflection on several food insecurity experiences including hunger, anxiety about household food access and preferences, and worrying about food adequacy (Headey and Ecker, 2013). The information generated by the HFIAS is used to assess the prevalence of household food insecurity (Coates et al. 2007).

Respondents were asked each of the HFIAS questions with a recall period of 4 weeks. This allowed them to assess, first, the occurrence of food insecurity, and then the frequency of different types of food insecurity occurrences. This allows a determination of whether food insecurity occurred rarely (once or twice), sometimes (three to ten times), or often (more than ten times) over a 4-week period (Coates et al. 2007; Headey and Ecker 2013).

Following Coates et al. (2007), we use HFIAS to classify households into four categories of household food insecurity access prevalence (HFIAP) status: (a) food secure, (b) mildly food insecure, (c) moderately food insecure, and (d) severely food insecure. In this article, we recast all the food insecurity indicators in the "positive scale" so that we can refer to them as FS indicators rather than food insecurity measures. Thus, we let $F S_{i}$ denote the category-severely food insecure $(F S=0)$, moderately food insecure ( $F S$ $=1$ ), mildly food insecure $(F S=2)$, and food secure $(F S=3)$-to which household $i$ belongs. These four categories present a measure of logically ordered household FS status of households in the two cities. We also define a binary food security indicator, FSD, simply as

$$
F S D=\left\{\begin{array}{l}
1 \text { if } F S=3 \\
0 \text { otherwise }
\end{array}\right.
$$

Lastly, rather than use the above categorical variables constructed from the HFIAS, which could lead to information loss, we simply use the HFIAS score, which ranges between 0 and 27. As before, we recast the food insecurity score into FS score, which we refer to as Household Food Security Access Scale Score (HFSASS) by simply subtracting the HFIAS score from 27 so that the larger the value of the score the more food secure a household is.

The validity of the HFIAS indicator has been tested comprehensively and found to have several advantages including the ability of the scale to capture psychological dimensions of food insecurity. It has been widely acknowledged as a valid and internally consistent tool for measuring the access component of FS (Becquey et al. 2010; Salarkia et al. 2014; Gebreyesus et al. 2015). Nonetheless, Headey and Ecker (2013) argue that the indicator lacks comparability across wealth and education groups in some contexts and has the tendency to underestimate food insecurity due to feelings of shame associated with admission of hunger.

Our main research question is whether the association between UA and FS depends on where agricultural production takes place-that is, whether in urban spaces (including peri-urban spaces) only, rural spaces only, or both. Thus, the main explanatory variable of interest is the location of crop and livestock 
production by urban households. Let prodloc denotes the category-nonparticipation in agriculture (prodloc $=1$ ), production in urban space only (prodloc $=$ 2 ), production in rural space only (prodloc $=3$ ), and production in both urban and rural spaces (prodloc $=3$ ) -to which urban household $i$ belongs. Differences in FS between the four groups of households are undetermined a priori because, as our conceptual model in equation (1) shows, urban households could achieve FS without food self-provisioning.

\section{Empirical econometric model}

We first model the association between FS and urban household participation in agriculture using the FS score (HFSASS) as the dependent variable. We use the Tobit estimator because nearly $47 \%$ of households did not experience food insecurity and therefore have the maximum score of 27 . The model can be written as:

$$
\begin{aligned}
& \text { hfsass } f_{i}^{*}=\alpha+\delta_{1} \text { Nonp }_{i}+\delta_{2} \text { Uonly }_{i}+\delta_{3} \text { Ronly }+\beta^{\prime} X_{i}+\varepsilon_{i} ; \text { where } \varepsilon_{i} \sim \text { Normal }\left(0, \sigma_{\varepsilon}^{2}\right) \\
& \text { hfsass }=\max \left(\text { hfsass }_{i}^{*}, 27\right)
\end{aligned}
$$

where Nonp, Uonly, and Ronly are the urban agriculture participation categories, meaning that $U a n d R$ is the base category;. $X_{i}$ is the vector of control variables; and $\varepsilon_{i}$ is the random error term.

Second, we use the probit estimator when the dependent variable is the binary FS indicator:

$$
F S D_{i}^{*}=\alpha+\gamma_{1} \text { Nonp }_{i}+\gamma_{2} \text { Uonly }_{i}+\gamma_{3} \text { Ronly }+\beta^{\prime} X_{i}+\varepsilon_{i},
$$

where $F S D_{i}^{*}$ is the latent unobserved level of FS for household $i$, which is related to the binary outcome $F S D_{i}$ by

$$
F S D_{i}= \begin{cases}1 & \text { if } F S D_{i}^{*}>0 \\ 0 & \text { otherwise }\end{cases}
$$

Finally, since the household food security access prevalence ( $h f s a p$ ) status indicator is ordinal, we specify an ordered probit model. The probability of observing a given $h f s a p$ status is estimated as:

$$
\begin{aligned}
h f_{s a p_{i}^{*}}^{*} & =\alpha+\phi_{1} \text { Nonp }_{i}+\phi_{2} \text { Uonly }_{i}+\phi_{3} \text { Ronly }_{+}+\beta^{\prime} X_{i}+\varepsilon_{i}, \text { hfsap }_{i}=j \text { if } \mu_{j-1} \\
& <h \text { ssap }_{i}^{*}<\mu_{i}
\end{aligned}
$$

where $\mu$ is the threshold parameter (or the number of possible outcomes, which in this case is four); $\varepsilon$ is assumed to be normally distributed; and all other variables and parameters are as defined earlier.

Our choice of control variables in the vector $X$ of Eqs. (3)-(5) was informed by the conceptual model in Eq. (1), which is based on the food security literature (e.g., Burchi and De Muro 2016; Frelat et al. 2016). These include household demographic characteristics, human capital indicators, income, nonfarm employment, stock of wealth in the form of livestock and other assets, and social network capital that could manifest in the form of private cash and kind transfers. An idiosyncratic shock could render an otherwise food secure 
household insecure. Therefore, we include indicators such as chronic illness, unemployment, and indebtedness as control variables. Finally, the full sample regressions contain a city dummy as an explanatory variable to capture cityspecific effects.

\section{Results and discussion}

\section{Descriptive analysis}

Our survey data shows that about $44 \%$ of households in the two cities produced crops and/or raised livestock, whether in urban or rural spaces or both-some estimates in the literature (Zezza and Tasciotti 2010) reported participation rates between $11 \%$ and $69 \%$. Participation in agriculture does not differ significantly across the two cities-about $44 \%$ in Techiman and $43 \%$ in Tamale ( $p$ value $=$ 0.506). For those involved in agriculture, production in only urban spaces (Uonly) was more common than production in rural spaces only (Ronly)-about $48 \%$ versus $41 \%$. Only about $12 \%$ of those engaged in agriculture produced in both urban and rural areas (UandR).

Less than half of households in each city (about $48 \%$ in Techiman and $47 \%$ and Tamale) could be classified as food secure-the rest experienced mild to severe food insecurity (Fig. 1). It is also striking that even in these urban areas, nearly one in every five households experienced severe food insecurity. From their survey of "low- and middleincome residents of Accra," Tukolske et al. (2018) reported that about 70\% experienced mild to severe food insecurity. These figures show that urban food insecurity is a serious problem that should not be ignored.

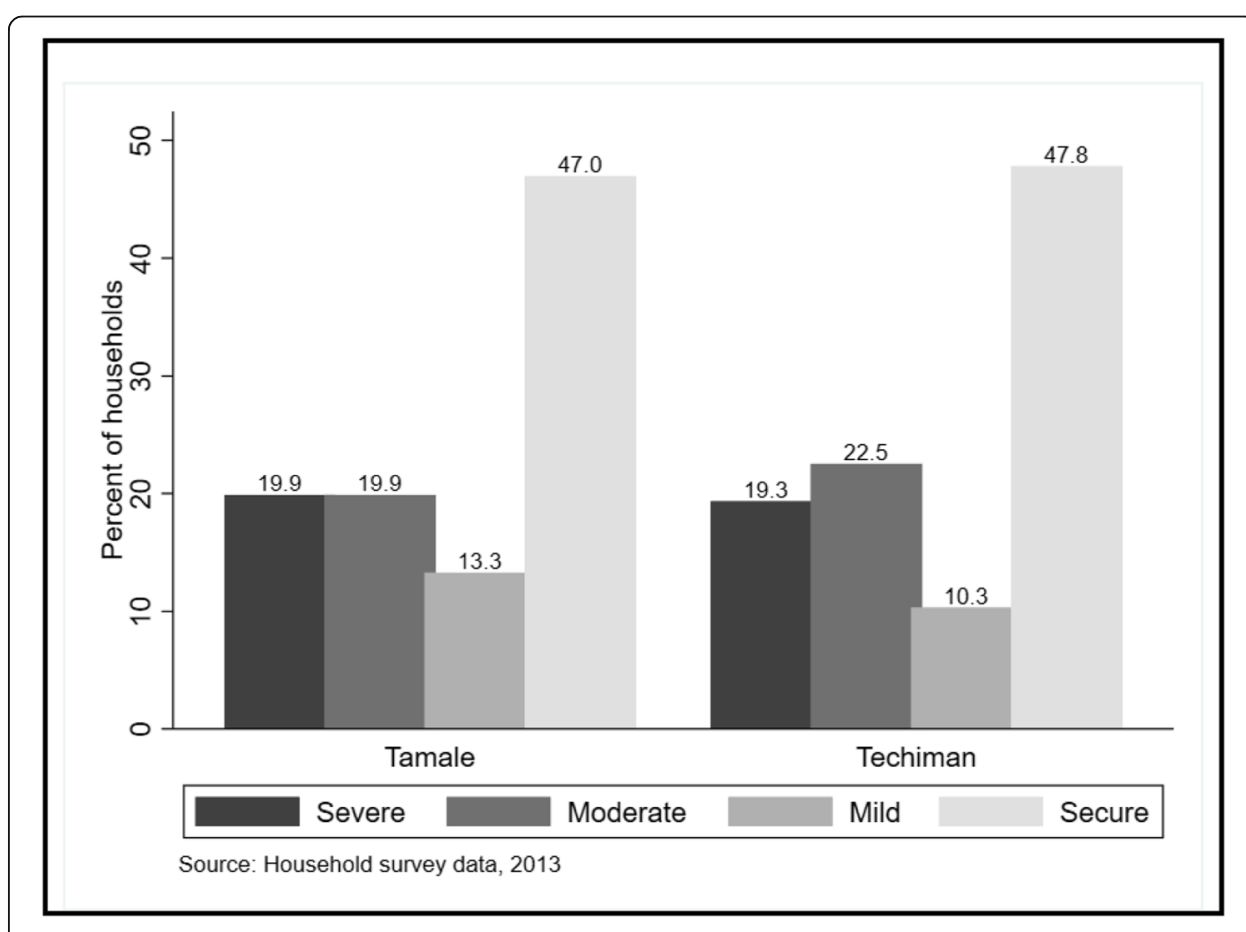

Fig. 1 Household food insecurity access prevalence (HFIAP) status by city 
Table 2 Sample mean statistics by agricultural participation categories

\begin{tabular}{|c|c|c|c|c|c|c|}
\hline \multirow[t]{2}{*}{ Variable } & \multirow[b]{2}{*}{$\begin{array}{l}\text { (1) Overall } \\
n=2004\end{array}$} & \multicolumn{4}{|c|}{ Categories of engagement in agriculture } & \multirow[b]{2}{*}{$\begin{array}{l}\text { (6) } p \\
\text { value }\end{array}$} \\
\hline & & $\begin{array}{l}\text { (2) No agric.(Nonp) } \\
n=1130\end{array}$ & $\begin{array}{l}\text { (3) Urban only } \\
\text { (Uonly) } n=417\end{array}$ & $\begin{array}{l}\text { (4) Rural only } \\
\text { (Ronly) } n=354\end{array}$ & $\begin{array}{l}\text { (5) Urban and rural } \\
(\text { UandR) } n=103\end{array}$ & \\
\hline $\begin{array}{l}\text { Food security } \\
\text { score (0-27) }\end{array}$ & 23.26 & 23.06 & 23.68 & 22.92 & 24.89 & 0.001 \\
\hline \multicolumn{7}{|l|}{$\begin{array}{l}\text { Food security } \\
\text { status: }\end{array}$} \\
\hline $\begin{array}{l}\text { Severely } \\
\text { insecure }\end{array}$ & 0.196 & 0.207 & 0.197 & 0.184 & 0.117 & 0.148 \\
\hline $\begin{array}{l}\text { Moderately } \\
\text { insecure }\end{array}$ & 0.212 & 0.216 & 0.182 & 0.263 & 0.117 & 0.004 \\
\hline $\begin{array}{l}\text { Mildly } \\
\text { insecure }\end{array}$ & 0.118 & 0.103 & 0.127 & 0.141 & 0.165 & 0.074 \\
\hline $\begin{array}{l}\text { Food } \\
\text { secure }\end{array}$ & 0.474 & 0.474 & 0.494 & 0.412 & 0.602 & 0.005 \\
\hline $\begin{array}{l}\text { Commercial } \\
\text { orientation }^{\dagger}\end{array}$ & 0.641 & - & 0.556 & 0.686 & 0.825 & 0.000 \\
\hline $\begin{array}{l}\text { Female HH } \\
\text { head }\end{array}$ & 0.222 & 0.274 & 0.201 & 0.124 & 0.058 & 0.000 \\
\hline $\begin{array}{l}\text { Age of HH } \\
\text { head }\end{array}$ & 44.61 & 41.52 & 48.59 & 47.83 & 51.23 & 0.000 \\
\hline $\begin{array}{l}\text { Age of } \\
\text { spouse }\end{array}$ & 38.33 & 36.89 & 41.25 & 39.25 & 39.14 & 0.000 \\
\hline $\begin{array}{l}\text { Married HH } \\
\text { head }\end{array}$ & 0.756 & 0.696 & 0.794 & 0.856 & 0.922 & 0.000 \\
\hline $\begin{array}{l}\text { Years } \\
\text { schooling: HH } \\
\text { head }\end{array}$ & 5.691 & 6.432 & 5.449 & 4.061 & 4.152 & 0.000 \\
\hline $\begin{array}{l}\text { Years } \\
\text { schooling: } \\
\text { spouse }\end{array}$ & 4.542 & 5.166 & 4.456 & 3.428 & 1.872 & 0.000 \\
\hline $\begin{array}{l}\text { Years } \\
\text { schooling: } \\
\text { other }\end{array}$ & 0.460 & 0.380 & 0.561 & 0.545 & 0.631 & 0.000 \\
\hline $\mathrm{HH}$ size & 4.741 & 4.171 & 5.242 & 5.559 & 6.146 & 0.000 \\
\hline $\begin{array}{l}\text { Under-15- } \\
\text { year-olds }\end{array}$ & 1.700 & 1.526 & 1.861 & 1.960 & 2.068 & 0.000 \\
\hline $\begin{array}{l}\text { Above-64- } \\
\text { year-olds }\end{array}$ & 0.177 & 0.131 & 0.223 & 0.237 & 0.291 & 0.000 \\
\hline $\begin{array}{l}\text { Working-age } \\
\text { members }\end{array}$ & 2.778 & 2.434 & 3.072 & 3.254 & 3.728 & 0.000 \\
\hline $\begin{array}{l}\text { Share of } \\
\text { dependants }\end{array}$ & 0.360 & 0.349 & 0.374 & 0.380 & 0.347 & 0.102 \\
\hline $\begin{array}{l}\text { Nuclear } \\
\text { household }\end{array}$ & 0.562 & 0.544 & 0.568 & 0.610 & 0.563 & 0.183 \\
\hline $\begin{array}{l}\text { Receives cash } \\
\text { transfer }\end{array}$ & 0.194 & 0.217 & 0.199 & 0.124 & 0.165 & 0.001 \\
\hline $\begin{array}{l}\text { Receives food } \\
\text { transfer }\end{array}$ & 0.309 & 0.338 & 0.254 & 0.294 & 0.272 & 0.010 \\
\hline $\begin{array}{l}\text { Nonfarm } \\
\text { income } \\
\text { dummy }\end{array}$ & 0.876 & 0.896 & 0.847 & 0.850 & 0.874 & 0.023 \\
\hline $\begin{array}{l}\text { Nonfarm } \\
\text { income } \\
\text { earners }\end{array}$ & 1.561 & 1.515 & 1.614 & 1.619 & 1.650 & 0.142 \\
\hline Livestock & 0.289 & & 0.635 & 0.644 & 0.835 & 0.000 \\
\hline
\end{tabular}


Table 2 Sample mean statistics by agricultural participation categories (Continued)

\begin{tabular}{|c|c|c|c|c|c|c|}
\hline \multirow[t]{2}{*}{ Variable } & \multirow[b]{2}{*}{$\begin{array}{l}\text { (1) Overall } \\
n=2004\end{array}$} & \multicolumn{4}{|c|}{ Categories of engagement in agriculture } & \multirow[b]{2}{*}{$\begin{array}{l}\text { (6) } p \\
\text { value }\end{array}$} \\
\hline & & $\begin{array}{l}\text { (2) No agric.(Nonp) } \\
n=1130\end{array}$ & $\begin{array}{l}\text { (3) Urban only } \\
\text { (Uonly) } n=417\end{array}$ & $\begin{array}{l}\text { (4) Rural only } \\
\text { (Ronly) } n=354\end{array}$ & $\begin{array}{l}\text { (5) Urban and rural } \\
(\text { UandR) } n=103\end{array}$ & \\
\hline \multicolumn{7}{|l|}{ producer } \\
\hline $\begin{array}{l}\text { Monthly pc } \\
\text { income (US\$) }\end{array}$ & 80.41 & 86.17 & 77.92 & 65.85 & 77.28 & 0.024 \\
\hline Own house & 0.312 & 0.275 & 0.393 & 0.308 & 0.398 & 0.000 \\
\hline $\begin{array}{l}\text { Chronically } \\
\text { sick HH head }\end{array}$ & 0.158 & 0.156 & 0.163 & 0.161 & 0.155 & 0.984 \\
\hline $\begin{array}{l}\text { Chronically } \\
\text { sick partner }\end{array}$ & 0.095 & 0.073 & 0.120 & 0.127 & 0.117 & 0.003 \\
\hline $\begin{array}{l}\text { Chronically } \\
\text { sick member }\end{array}$ & 0.130 & 0.111 & 0.129 & 0.175 & 0.184 & 0.005 \\
\hline Indebted & 0.107 & 0.091 & 0.144 & 0.096 & 0.165 & 0.005 \\
\hline $\begin{array}{l}\text { Unemployed } \\
\text { HH head }\end{array}$ & 0.055 & 0.080 & 0.026 & 0.020 & 0.019 & 0.000 \\
\hline $\begin{array}{l}\text { Unemployed } \\
\text { spouse }\end{array}$ & 0.076 & 0.087 & 0.062 & 0.054 & 0.087 & 0.128 \\
\hline $\begin{array}{l}\text { Unemployed } \\
\text { adult }\end{array}$ & 0.163 & 0.142 & 0.177 & 0.215 & 0.146 & 0.010 \\
\hline
\end{tabular}

The $p$ values are based on joint F-statistics for the hypothesis that the value of a given variable is identical across the four categories of urban household engagement in agriculture tCommercial orientation is defined as the share of UA participating households that produced and sold some of their output

Table 2 presents mean summary statistics of variables employed in the regression analyses by the four agriculture engagement categories (i.e., Nonp, Uonly, Ronly, and UandR). The average household food security access scale score is about 23 out of a maximum score of 27; the scores are not statistically identical across the four groups of urban households, as the $p$ value in column (6) shows. Urban households who produced food in both urban and rural areas have a higher mean FS score than the other groups. The Household Food Insecurity Access Prevalence (HFIAP) status indicator shows that severe food insecurity is least common among UandR households. Similarly, a higher proportion (60\%) UandR households were food secure compared with only $47 \%$ in the overall sample.

The descriptive analytical results thus show that the opportunity for agricultural production in both urban and rural spaces could enhance urban household FS. This is probably because such an opportunity helps relax the land constraint to production in urban areas.

As the majority of studies in SSA have shown (Poulsen et al. 2015), semisubsistence is the main motive for UA participation in our sample. In the overall sample, about $64 \%$ of UA participating households sold some of their output; about $35 \%$ produced for home consumption only-which is contrary to the conclusion reached by Zezza and Tasciotti (2010) that the most common motivation for UA is subsistence. Producing solely for sale is rare in our sample (only 10 households produced for the market only), which is consistent with findings in the UA literature for low-income countries (Poulsen et al. 2015). What is unique about our study is the finding that the magnitude of commercial orientation 
differs significantly across the three groups of participating households, with the UandR group being the most commercially oriented, probably due to access to more resources.

Most of the other variables (22 out of 27) reported in Table 2 also show significant differences across the four UA participation categories. For example, while women are key actors in the UA value chain, their participation as primary producers is lower than that of men (30\% versus $47 \%$ ). Females tend to be underrepresented in the UandR group in particular. Level of education is highest among nonparticipating household (Nonp) and so is participation in nonfarm employment, as could be expected; Nonp households are also the smallest in size, and they have the highest mean per capita income.

We note that the relatively higher per capita incomes received by UA nonparticipating households in the two cities did not necessarily translate into better FS. This suggests that as others (Korth et al. 2014) have cautioned, relying on food markets alone may not guarantee household FS. This result is not overly surprising because, besides income, food access by urban households is also conditioned by food prices and spatial proximity to markets (Crush and Frayne 2011).

\section{Regression results and discussion}

Fitting one model for all observations across the two cities assumes that the coefficients do not vary significantly between the cities. This is a strong assumption given the differing characteristics of the two cities such as size, land ownership structure, and agroecology. More formally, a likelihood-ratio test for the null hypothesis that the coefficients of the models do not differ significantly across the two cities is rejected at the $1 \%$ level. Therefore, we report results from the overall and city-specific samples.

Before presenting our main results, it is worth testing the more general hypothesis that UA participants and nonparticipants have the same food security status, on average. The results (available from the authors) show that, irrespective of FS indicator, there is insufficient evidence to reject the null hypothesis, meaning that participating and non-participating households have the same average level of FS in the full sample and for each city.

Our main results, which are from estimating Eqs. (3)-(5) are presented in Tables 3, 4, 5, and 6. If the finding in the descriptive analysis that urban households who produced food in both urban and rural spaces were more food secure than other urban households is to be sustained, then the estimates of $\delta_{k}$, $\gamma_{k}$, and $\phi_{k}$ for $k=1,2,3$ in Eqs. (3)-(5) should all be negative and statistically different from zero at conventional levels. The full sample Tobit and Probit average marginal effects (columns 1 and 4 of Table 3) show negative signs on the main parameters of interest and are all statistically significant at the $1 \%$ or $5 \%$ levels. The estimated full sample results thus support the descriptive result that, on average, households who had the opportunity of agricultural production in both urban and rural spaces (UandR) attained significantly higher FS than all other groups of urban households. For example, the largest gap in FS score 
Table 3 Tobit and probit estimates of household participation in agriculture and food security (AME)

\begin{tabular}{|c|c|c|c|c|c|c|}
\hline \multirow[t]{3}{*}{ Variables } & \multicolumn{3}{|c|}{ Tobit for HFSAS score (Eq. 3) } & \multicolumn{3}{|c|}{ Probit for FSD (Eq. 4) } \\
\hline & $(1)$ & (2) & (3) & $(4)$ & (5) & (6) \\
\hline & $\begin{array}{l}\text { Full } \\
\text { sample }\end{array}$ & Techiman & Tamale & $\begin{array}{l}\text { Full } \\
\text { sample }\end{array}$ & Techiman & Tamale \\
\hline \multicolumn{7}{|l|}{$\begin{array}{l}\text { Participation in agriculture (ref. is } \\
\text { UandR) }\end{array}$} \\
\hline Nonp & $-1.631^{* * *}$ & -0.594 & $-\overline{2.043^{* * *}}$ & $-0.166^{* * *}$ & 0.014 & $\overline{-} .253^{* * *}$ \\
\hline Uonly & $-1.263^{* *}$ & -0.659 & $-1.201^{*}$ & $-0.136^{* * *}$ & -0.010 & $-0.141^{* *}$ \\
\hline Ronly & $-1.850^{* * *}$ & -0.853 & $-\overline{2.282^{* * *}}$ & $-0.190^{* * *}$ & -0.027 & $\overline{0.263^{* * *}}$ \\
\hline Female HH head & $-0.712^{* *}$ & $-\overline{1.802^{* * *}}$ & -0.042 & $-0.122^{* * *}$ & $-\overline{-}^{-235^{* * *}}$ & -0.050 \\
\hline Age of $\mathrm{HH}$ head & 0.020 & $0.052^{* *}$ & 0.000 & 0.001 & $0.005^{* *}$ & -0.002 \\
\hline Age of spouse & -0.016 & -0.036 & -0.017 & -0.000 & -0.003 & 0.001 \\
\hline Married HH head & 0.297 & 0.398 & 0.055 & -0.015 & -0.000 & -0.033 \\
\hline Years schooling: HH head & 0.004 & -0.019 & 0.010 & -0.003 & -0.005 & -0.002 \\
\hline Years schooling: spouse & $0.210^{* * *}$ & $0.461^{* * *}$ & $0.063^{*}$ & $0.023^{* * *}$ & $0.046^{* * *}$ & $0.009^{*}$ \\
\hline Years schooling: other adult & 0.354 & 0.166 & $0.628^{*}$ & 0.029 & -0.001 & $0.080^{* *}$ \\
\hline HH size & 0.059 & $0.203^{* *}$ & -0.052 & 0.008 & 0.016 & 0.001 \\
\hline Share of dependants & 0.421 & -0.331 & $1.137^{*}$ & 0.046 & -0.030 & $0.133^{*}$ \\
\hline Received cash transfer & 0.005 & 0.114 & -0.230 & 0.017 & 0.049 & -0.031 \\
\hline Received food transfer & 0.324 & 0.311 & 0.159 & 0.036 & 0.040 & 0.009 \\
\hline No. of nonfarm income earners & 0.051 & -0.192 & $0.311^{* *}$ & 0.010 & -0.014 & $0.035^{*}$ \\
\hline Monthly per capita income & $0.011^{* * *}$ & $0.009^{* * *}$ & $0.014^{* * *}$ & $0.001^{* * *}$ & $0.001^{* * *}$ & $0.001^{* * *}$ \\
\hline Livestock producer & 0.054 & 0.219 & -0.143 & -0.031 & 0.004 & -0.087 \\
\hline Owns dwelling & 0.282 & 0.095 & 0.218 & $0.049^{* *}$ & 0.009 & $0.068^{* *}$ \\
\hline Chronically sick HH head & $-0.594^{* * *}$ & -0.416 & $-0.616^{* *}$ & $-0.076^{* *}$ & -0.066 & -0.071 \\
\hline Chronically sick spouse & $-0.611^{* *}$ & $-0.764^{*}$ & -0.395 & -0.032 & -0.061 & 0.009 \\
\hline Chronically HH member & -0.313 & -0.372 & -0.237 & -0.053 & -0.062 & -0.040 \\
\hline Indebted & 0.050 & $-0.773^{* *}$ & $1.508^{* * *}$ & -0.016 & $-0.098^{* *}$ & $0.109^{*}$ \\
\hline Unemployed HH head & $-1.521^{* * *}$ & $-\overline{1.976^{* * *}}$ & $-1.039^{* *}$ & $-0.126^{* * *}$ & $-\overline{0.169^{* * *}}$ & -0.089 \\
\hline Unemployed spouse & $-0.936^{* * *}$ & $-\overline{1.335^{* * *}}$ & -0.496 & -0.060 & $-0.129^{* *}$ & -0.000 \\
\hline Unemployed HH member & $-0.504^{* *}$ & -0.282 & $-0.634^{* *}$ & $-0.062^{*}$ & -0.008 & $-0.101^{* *}$ \\
\hline Techiman & -0.187 & & & 0.003 & & \\
\hline Observations & 2004 & 1008 & 996 & 2004 & 1008 & 996 \\
\hline Log-likelihood value & -4295 & -2148 & -2102 & -1263 & -619.7 & -607.5 \\
\hline Pseudo $R^{2}$ & 0.0763 & 0.0842 & 0.0873 & 0.1292 & 0.152 & 0.158 \\
\hline
\end{tabular}

$A M E$ average marginal effect

${ }^{* * *} p<0.01,{ }^{* *} p<0.05,{ }^{*} p<0.1$

(about 1.8 or 7 percentage points on the percentage scale) was between UandR and Ronly households. Similarly, the probability of being food secure is about 19 percentage points lower for Ronly household than for UandR households (column 4). 
Table 4 Ordered probit estimates of participation in agriculture and food security (overall sample)

\begin{tabular}{|c|c|c|c|c|c|}
\hline \multirow[t]{3}{*}{ Variables } & \multirow[b]{2}{*}{ (1) } & \multicolumn{4}{|c|}{ Average marginal effects } \\
\hline & & $(2)$ & (3) & $(4)$ & (5) \\
\hline & Coef. & Severe & Moderate & Mild & Secure \\
\hline \multicolumn{6}{|c|}{ Participation in agriculture (ref. is UandR } \\
\hline Nonp & $-0.437^{* * *}$ & 0.095 & 0.052 & 0.010 & -0.158 \\
\hline Uonly & $-0.385^{* * *}$ & 0.082 & 0.047 & 0.010 & -0.139 \\
\hline Ronly & $-0.449^{* * *}$ & 0.099 & 0.054 & 0.010 & -0.163 \\
\hline Female HH head & $-0.264^{* * *}$ & 0.071 & 0.024 & -0.000 & -0.095 \\
\hline Age of $\mathrm{HH}$ head & $0.007^{* *}$ & -0.002 & -0.001 & -0.000 & 0.003 \\
\hline Age of spouse & -0.005 & 0.001 & 0.000 & 0.000 & -0.002 \\
\hline Married HH head & 0.067 & -0.017 & -0.007 & -0.000 & 0.024 \\
\hline Years schooling: HH head & -0.000 & 0.000 & 0.000 & 0.000 & -0.000 \\
\hline Years schooling: spouse & $0.060^{* * *}$ & -0.015 & -0.006 & -0.000 & 0.022 \\
\hline Years schooling: other adult & 0.070 & -0.018 & -0.007 & -0.000 & 0.025 \\
\hline $\mathrm{HH}$ size & 0.021 & -0.005 & -0.002 & -0.000 & 0.008 \\
\hline Share of dependants & 0.009 & -0.002 & -0.001 & -0.000 & 0.003 \\
\hline Received cash transfer & 0.013 & -0.003 & -0.001 & -0.000 & 0.005 \\
\hline Received food transfer & $0.102^{*}$ & -0.026 & -0.010 & -0.001 & 0.037 \\
\hline No. of nonfarm income earners & 0.022 & -0.006 & -0.002 & -0.000 & 0.008 \\
\hline Monthly per capita income & $0.003^{* * *}$ & -0.001 & -0.000 & -0.000 & 0.001 \\
\hline Livestock producer & -0.029 & 0.007 & 0.003 & 0.000 & -0.011 \\
\hline Owns dwelling & $0.100^{*}$ & -0.025 & -0.010 & -0.001 & 0.036 \\
\hline Chronically sick HH head & $-0.186^{* *}$ & 0.050 & 0.017 & -0.000 & -0.067 \\
\hline Chronically sick spouse & $-0.176^{*}$ & 0.048 & 0.016 & -0.000 & -0.063 \\
\hline Chronically HH member & -0.069 & 0.018 & 0.007 & 0.000 & -0.025 \\
\hline Indebted & -0.025 & 0.006 & 0.002 & 0.000 & -0.009 \\
\hline Unemployed $\mathrm{HH}$ head & $-0.398^{* * *}$ & 0.116 & 0.029 & -0.005 & -0.140 \\
\hline Unemployed spouse & $-0.222^{* *}$ & 0.061 & 0.019 & -0.001 & -0.079 \\
\hline Unemployed HH member & $-0.229 * * *$ & 0.062 & 0.021 & -0.000 & -0.082 \\
\hline Techiman & 0.013 & -0.003 & -0.001 & -0.000 & 0.005 \\
\hline$\mu(1)$ & $-0.602^{* * *}$ & & & & \\
\hline$\mu(2)$ & 0.078 & & & & \\
\hline$\mu(3)$ & $0.405^{*}$ & & & & \\
\hline Observations & 2004 & & & & \\
\hline Log-likelihood value & -2370 & & & & \\
\hline Pseudo $R^{2}$ & 0.097 & & & & \\
\hline
\end{tabular}

${ }^{* * *} p<0.01,{ }^{* *} p<0.05,{ }^{*} p<0.1$

The ordered probit results (Tables 4, 5, and 6) tell the same story as the Tobit and Probit estimates. For example, while the average probability of being severely food insecure is about 8 and 10 percentage points higher for Uonly and Ronly households compared with $U a n d R$ households (column 2 of Table 4), the corresponding average probability of being food secure is about 14 and 16 percentage points lower for Uonly and Ronly households (column 5 of Table 4). Results from the city-specific estimates show that the agriculture participation-associated differences in FS are driven by the Tamale sample. 
Table 5 Ordered probit estimates of participation in agriculture and food security (Techiman)

\begin{tabular}{|c|c|c|c|c|c|}
\hline \multirow[t]{3}{*}{ Variables } & \multirow[b]{2}{*}{ (1) } & \multicolumn{4}{|c|}{ Average marginal effects } \\
\hline & & (2) & (3) & (4) & (5) \\
\hline & Coef. & Severe & Moderate & Mild & Secure \\
\hline \multicolumn{6}{|c|}{ Participation in agriculture (ref. is UandR) } \\
\hline Nonp & -0.090 & 0.021 & 0.010 & 0.001 & -0.031 \\
\hline Uonly & -0.178 & 0.043 & 0.018 & 0.001 & -0.062 \\
\hline Ronly & -0.125 & 0.030 & 0.013 & 0.001 & -0.044 \\
\hline Female HH head & $-0.631^{* * *}$ & 0.166 & 0.050 & -0.003 & -0.213 \\
\hline Age of HH head & $0.018^{* * *}$ & -0.005 & -0.002 & -0.000 & 0.006 \\
\hline Age of spouse & $-0.012^{*}$ & 0.003 & 0.001 & 0.000 & -0.004 \\
\hline Married HH head & 0.120 & -0.030 & -0.012 & -0.000 & 0.042 \\
\hline Years schooling: HH head & -0.011 & 0.003 & 0.001 & 0.000 & -0.004 \\
\hline Years schooling: spouse & $0.138^{* * *}$ & -0.034 & -0.014 & -0.000 & 0.048 \\
\hline Years schooling: other adult & 0.007 & -0.002 & -0.001 & -0.000 & 0.002 \\
\hline HH size & $0.053^{* *}$ & -0.013 & -0.005 & -0.000 & 0.018 \\
\hline Share of dependants & -0.166 & 0.041 & 0.017 & 0.001 & -0.058 \\
\hline Received cash transfer & 0.001 & -0.000 & -0.000 & -0.000 & 0.000 \\
\hline Received food transfer & 0.094 & -0.023 & -0.010 & -0.000 & 0.033 \\
\hline No. of nonfarm income earners & -0.029 & 0.007 & 0.003 & 0.000 & -0.010 \\
\hline Monthly per capita income & $0.002^{* * *}$ & -0.001 & -0.000 & -0.000 & 0.001 \\
\hline Livestock producer & 0.015 & -0.004 & -0.002 & -0.000 & 0.005 \\
\hline Owns dwelling & 0.025 & -0.006 & -0.002 & -0.000 & 0.009 \\
\hline Chronically sick HH head & -0.162 & 0.041 & 0.015 & -0.000 & -0.057 \\
\hline Chronically sick spouse & -0.194 & 0.051 & 0.017 & -0.001 & -0.067 \\
\hline Chronically HH member & -0.086 & 0.022 & 0.008 & 0.000 & -0.030 \\
\hline Indebted & $-0.280^{* *}$ & 0.074 & 0.024 & -0.001 & -0.096 \\
\hline Unemployed $\mathrm{HH}$ head & $-0.516^{* * *}$ & 0.148 & 0.033 & -0.008 & -0.173 \\
\hline Unemployed spouse & $-0.461^{* * *}$ & 0.129 & 0.031 & -0.006 & -0.155 \\
\hline Unemployed HH member & -0.145 & 0.037 & 0.013 & -0.000 & -0.051 \\
\hline$\mu(1)$ & 0.014 & & & & \\
\hline$\mu(2)$ & $0.766^{* *}$ & & & & \\
\hline$\mu(3)$ & $1.061^{* * *}$ & & & & \\
\hline Observations & 1008 & & & & \\
\hline Log-likelihood value & -1150 & & & & \\
\hline Pseudo $R^{2}$ & 0.122 & & & & \\
\hline
\end{tabular}

${ }^{* * *} p<0.01,{ }^{* *} p<0.05,{ }^{*} p<0.1$

The differing city-specific results regarding our main hypothesis point to important city-specific nuances, which could be explained by contextual differences. For example, the production of vegetables is more common in Tamale due to its metropolitan status and the accompanying high demand from a relatively high population of public servants and expatriates. Another important contextual difference between the two cities is access to land and the motivation for UA. Whereas Techiman lands are mostly vested in the "stool" (i.e., the royal or chiefly family), a significant share of the land used for UA in Tamale is under state control (Drechsel et al. 2014). Due to the different land 
Table 6 Ordered probit estimates of participation in agriculture and food security (Tamale)

\begin{tabular}{|c|c|c|c|c|c|}
\hline \multirow[t]{3}{*}{ Variables } & \multirow{3}{*}{$\begin{array}{l}(1) \\
\text { Coef. }\end{array}$} & \multicolumn{4}{|c|}{ Average marginal effects } \\
\hline & & \multirow{2}{*}{$\begin{array}{l}\text { (2) } \\
\text { Severe }\end{array}$} & \multirow{2}{*}{$\begin{array}{l}(3) \\
\text { Moderate }\end{array}$} & \multirow{2}{*}{$\begin{array}{l}\text { (4) } \\
\text { Mild }\end{array}$} & \multirow{2}{*}{$\begin{array}{l}\text { (5) } \\
\text { Secure }\end{array}$} \\
\hline & & & & & \\
\hline \multicolumn{6}{|c|}{ Participation in agriculture (ref. is UandR) } \\
\hline Nonp & $-0.609^{* * *}$ & 0.128 & 0.069 & 0.018 & -0.216 \\
\hline Uonly & $-0.388^{* *}$ & 0.073 & 0.048 & 0.016 & -0.137 \\
\hline Ronly & $-0.612^{* * *}$ & 0.129 & 0.070 & 0.018 & -0.217 \\
\hline Female HH head & -0.053 & 0.014 & 0.005 & 0.000 & -0.019 \\
\hline Age of HH head & 0.000 & -0.000 & -0.000 & -0.000 & 0.000 \\
\hline Age of spouse & -0.004 & 0.001 & 0.000 & 0.000 & -0.001 \\
\hline Married HH head & -0.032 & 0.008 & 0.003 & 0.000 & -0.011 \\
\hline Years schooling: HH head & 0.004 & -0.001 & -0.000 & -0.000 & 0.002 \\
\hline Years schooling: spouse & 0.017 & -0.004 & -0.002 & -0.000 & 0.006 \\
\hline Years schooling: other adult & $0.177^{*}$ & -0.045 & -0.017 & -0.001 & 0.063 \\
\hline HH size & -0.004 & 0.001 & 0.000 & 0.000 & -0.002 \\
\hline Share of dependants & 0.217 & -0.055 & -0.020 & -0.001 & 0.077 \\
\hline Received cash transfer & -0.037 & 0.009 & 0.003 & 0.000 & -0.013 \\
\hline Received food transfer & 0.052 & -0.013 & -0.005 & -0.000 & 0.018 \\
\hline No. of nonfarm income earners & $0.092^{* *}$ & -0.023 & -0.009 & -0.001 & 0.033 \\
\hline Monthly per capita income & $0.004^{* * *}$ & -0.001 & -0.000 & -0.000 & 0.001 \\
\hline Livestock producer & -0.106 & 0.027 & 0.010 & 0.000 & -0.037 \\
\hline Owns dwelling & 0.114 & -0.029 & -0.011 & -0.001 & 0.041 \\
\hline Chronically sick HH head & -0.173 & 0.046 & 0.015 & -0.000 & -0.061 \\
\hline Chronically sick spouse & -0.139 & 0.037 & 0.012 & 0.000 & -0.049 \\
\hline Chronically HH member & -0.045 & 0.012 & 0.004 & 0.000 & -0.016 \\
\hline Indebted & $0.365^{* *}$ & -0.082 & -0.040 & -0.009 & 0.130 \\
\hline Unemployed $\mathrm{HH}$ head & $-0.305^{*}$ & 0.085 & 0.023 & -0.003 & -0.106 \\
\hline Unemployed spouse & -0.014 & 0.004 & 0.001 & 0.000 & -0.005 \\
\hline Unemployed HH member & $-0.304^{* * *}$ & 0.083 & 0.025 & -0.001 & -0.107 \\
\hline$\mu(1)$ & $-1.013^{* * *}$ & & & & \\
\hline$\mu(2)$ & -0.362 & & & & \\
\hline$\mu(3)$ & 0.015 & & & & \\
\hline Observations & 996 & & & & \\
\hline Log-likelihood value & -1173 & & & & \\
\hline Pseudo $R^{2}$ & 0.109 & & & & \\
\hline
\end{tabular}

${ }^{* * *} p<0.01,{ }^{* *} p<0.05,{ }^{*} p<0.1$

ownership arrangements, the motivation for UA in the two cities also differs. Farming in urban Techiman is seen essentially as a strategy for ensuring land tenure security while UA in Tamale is motivated more by the commercial motive as households devote substantial amounts of resources to the production of vegetables for consumption and sale to other urbanites.

The qualitative interviews also show that crop production by women, particularly vegetables used in the preparation of local dishes, is encouraged around homes in Tamale. This provides women the opportunity to work on the farm 
while carrying out reproductive activities (cooking and caring for children), allowing men to commute to rural areas to farm. This result corroborates with the finding of Maxwell (1995) that UA allowed women to combine productive and child caregiving roles in Kampala. Indeed, according to our in-depth interviews, men in Tamale sometimes migrate temporarily to rural areas during the rainy reason to access more land for the production of staple crops while women and children cultivate the home gardens in the city.

We find other important predictors of urban household food security. In the interest of brevity, we focus the discussion on results in Table 3. The significant predictors in the full sample are sex of household head, women's education, income, and idiosyncratic shocks such as chronic illness and unemployment. Our results support findings in some of the existing FS literature that female-headed households are less likely to be food secure than male-headed households (Dzanku and Sarpong 2010; Bashir et al. 2012).

The significant gender difference, however, pertains to Techiman. For example, the estimated average probability of being food secure is about 23 percentage points lower for those living in female-headed households in Techiman compared with those living in male-headed households in that city. Women are key influencers in meeting household food and nutrition needs (Quisumbing et al. 1996; Rosegrant and Cline 2003). Mother's education level is particularly highly correlated with household FS in Techiman-an extra year of schooling by a mother is estimated to raise the average probability of being food secure by approximately 5 percentage points in Techiman; household head's educational level does not have a similar effect, however.

Income is important for achieving FS though the market arm as shown in the conceptual model. This is particularly important for urban households who are expected to rely more on food markets for meeting their food needs. As expected, income is positively correlated with FS in both cities. In the full sample, increasing per capita income by an extra $\$ 10$ monthly is estimated to increase the probability of being food secure by $1 \%$ point. Nonfarm employment seems more important for household food security in Tamale where an extra household member employed in a nonfarm activity is estimated to raise the probability of being food secure by approximately 3 percentage points. Owusu et al. (2011) provides similar evidence for rural communities in northern Ghana.

We find household-specific health and unemployment events to have very negative food security implications. For example, the presence of a chronically ill household head is estimated to reduce household average FS score by about 2 percentage points in the full sample; the presence of a chronically ill spouse carries an identical average FS reducing effect. Being indebted has contrasting FS effects in the two cities-a negative effect in Techiman but a positive effect in Tamale. In theory, borrowing is not necessarily a negative thing, it depends on how the borrowed funds are utilized.

\section{Robustness checks}

One could worry about whether the result that urban households who participated in agriculture in both urban and rural areas are more food secure is driven by endogeneity bias, not least as a result of omitted variable bias and/or reverse causality. First, omitted variable bias could arise through unobserved heterogeneity for which we need panel data to address and as such is a weakness of this study, as it is for all cross-sectional observational data. 
In the case of reverse causality, the key question is whether $\operatorname{UandR}$ households are more food secure because they produce in rural and urban areas or they are so because their individual characteristics that allows them to participate in both spaces make them less likely to be food insecure. This proposition is possible but unlikely for these urban households. First, as we have seen through the conceptual model, urban households do not need to engage in agriculture to be food secure ex ante. Second, Table 2 shows that UandR households are not the richest in terms of money matric indicators of welfare. They also have the least access to financial services, which is very low in the sample. The key endowments that are greater among UandR households than Nonp and Uonly households are household labor and livestock, which are control variables in the FS regressions.

However, as an econometric robustness check, we account for the possibility of endogenous selection as follows. We first estimate a multinomial logit model to predict the geography of agriculture participation. That is, we obtain Inverse Mills Ratios (IMRs) from regressing prodloc, which is the nominal agriculture participation indicator, on all exogenous variables, including identification variables or instruments. We then enter the IMRs into the FS equations to correct for potential endogeneity bias in the spirit of Heckman (1979). ${ }^{3}$ We use birthplace and parents occupation (full time farmer) as identifying variables. Being an indigene increases the likelihood of access to land for farming while parents' engagement in agriculture predicts current participation strongly in our data. We bootstrap the standard errors due the two-step nature of the procedure. Test for joint significance of the IMRs in the FS equations provides a test for endogeneity bias.

In the interest of brevity, we present the endogeneity corrected results for Eqs. (3) and (4) in Appendix Table 7. First, we note that none of the IMRs are individually significantly different from zero at even the $10 \%$ level. Second, the joint $F$ tests all yield $p$ values that are larger than 0.10 . With respect to the substantive results, we see that while our conclusions remain generally valid, correcting for potential endogeneity leads to slightly imprecise point estimates. For example, UandR households are only significantly more food secure than Nonp households at the 10\% level (Appendix Table 7, column 3). Our results should thus be interpreted with these issues in mind.

\section{Conclusion}

The received literature on the association between UA and FS has either focused on urban household's participation in agriculture irrespective of where the activity takes place, or restricted participation to production within urban and peri-urban areas, or more narrowly, production within build-up urban spaces. A recent systematic review of the UA literature (Abu Hatab et al. 2019b) pointed to the need to fill an important gap in the literature related to the role of rural-urban linkages, inter alia, in our understanding of urban food systems and urban FS. This article is, in part, a response to this call as it contributes to the UA literature by distinguishing between urban households' agricultural production activities in urban and rural areas and the implications for urban household FS. By disentangling urban household's participation in agriculture by geography of production activities, we have been able to pick up food security implications that would have been lost through an aggregation that ignores the geography of

${ }^{3}$ See Harou et al. (2016) for a more recent application of our approach. 
production. Additionally, the study is contextualized within small and medium-sized cities, breaking away from the large city bias that has characterized UA research in Africa as a whole and Ghana in particular.

Our survey data, which is representative of both UA participants and nonparticipants, shows a nontrivial but identical magnitude of participation in the two cities-about $44 \%$ overall. For the majority (about $88 \%$ ) of those participating, the agriculture activities took place either in urban or rural areas, with the rest producing in both rural and urban spaces. Consistent with the existing UA literature (Poulsen et al. 2015), semisubsistence is the primary motivation for participation in UA although about $35 \%$ of participants did so for home consumption only. We also observed that food insecurity is an important problem in the two cities, with more than half of all households experiencing some form of food poverty.

We have shown that if one ignores the geography of production, then the hypothesis that, on average, the level of urban household FS is the same for UA participants, and nonparticipants cannot be rejected. Thus, neither agricultural production in urban nor rural space alone was significantly associated with urban household food security. Once we distinguish between households who had the opportunity to produce in both urban and rural areas from those who produced in either urban or rural areas, we find that the former group was significantly more food secure. However, this result is driven by the sample in the medium-sized city (Tamale), where higher demand for vegetables, cultural norms, and relative scarcity of land for production within the city all combine to stimulate agricultural production in both rural and urban areas.

Our results provide justification for the call by Abu Hatab et al. (2019b) to take into account "rural-urban connectivity" when developing policies and practices related to urban food systems and FS. We thus further argue that the contribution of urban agriculture to urban household food security should be nuanced in terms of the geography of production. However, as others (Poulsen et al. 2015; Warren et al. 2015; Abu Hatab et al. 2019a) have shown, city context matters, and such heterogeneity needs to be recognized in UA policies and practices. As shown for Tamale, our results confirm that markets, not just production, are important if agriculture is to contribute substantially to urban household food security. Additionally, the harsh agroecological conditions in Tamale makes farming impossible without irrigation and thus pushes farmers to pursue urban farming in a more modern manner than in Techiman, which seems to result in better FS.

From a policy perspective, discussions about urban agriculture's potential contribution to poverty reduction need to be contextualized across city-types-clearly "one-size-fits-all policies" about UA should be avoided. In addition, as Abu Hatab et al. (2019b) have argued, our findings show that there is the need for urban and rural agriculture policies to be conceived in a complementary manner rather than treated as mutually exclusive because synergies could be harnessed in specific contexts as an effective poverty reduction strategy. Lastly, since urban FS goes beyond food self-provisioning (Crush and Frayne 2011; Korth et al. 2014), the problem of urban food insecurity can only be comprehensively tackled using a broad-based approach that addresses not only challenges facing UA but also access to decent jobs and food markets in general. 


\section{Appendix}

Table 7 Endogeneity corrected estimates of household participation in agriculture and FS (AME)

\begin{tabular}{|c|c|c|c|c|c|c|}
\hline \multirow[t]{3}{*}{ Variables } & \multicolumn{3}{|c|}{ Tobit for HFSAS score (Eq. 3) } & \multicolumn{3}{|c|}{ Probit for FSD (Eq. 4) } \\
\hline & (1) & $(2)$ & (3) & (4) & (5) & (6) \\
\hline & Overall & Techiman & Tamale & Full sample & Techiman & Tamale \\
\hline \multicolumn{7}{|l|}{$\begin{array}{l}\text { Participation in agriculture } \\
\text { (ref. is UandR) }\end{array}$} \\
\hline Nonp & $-1.474^{* *}$ & -0.756 & $-1.635^{*}$ & $-0.177^{* * *}$ & -0.015 & $-0.257^{* * *}$ \\
\hline Uonly & $-1.135^{* *}$ & -0.675 & $-0.742^{*}$ & $-0.136^{* *}$ & -0.011 & $-0.121^{* *}$ \\
\hline Ronly & $-1.756^{* * *}$ & -0.830 & $-2.058^{* * *}$ & $-0.191^{* * *}$ & -0.028 & $-0.258^{* * *}$ \\
\hline Female HH head & -1.732 & $-2.282^{* * *}$ & 0.351 & -0.258 & $-0.300^{* * *}$ & -0.030 \\
\hline Age of HH head & -0.023 & 0.044 & 0.001 & -0.003 & 0.005 & -0.002 \\
\hline Age of spouse & 0.003 & -0.034 & -0.007 & 0.002 & -0.002 & 0.002 \\
\hline Married HH head & -0.043 & 0.458 & 0.088 & -0.043 & 0.025 & -0.016 \\
\hline Years schooling: HH head & -0.116 & -0.041 & 0.014 & -0.015 & -0.006 & -0.001 \\
\hline Years schooling: spouse & $0.382^{*}$ & $0.517^{* * *}$ & 0.120 & 0.043 & $0.053^{* * *}$ & 0.016 \\
\hline Years schooling: adult & 0.157 & 0.461 & 0.655 & 0.013 & 0.038 & 0.085 \\
\hline HH size & -0.037 & $0.189^{*}$ & $-0.140^{*}$ & -0.004 & 0.012 & -0.009 \\
\hline Share of dependants & 1.681 & 0.513 & $1.904^{* *}$ & 0.172 & 0.036 & $0.205^{* *}$ \\
\hline Received cash transfer & -0.643 & -0.019 & -0.401 & -0.056 & 0.025 & -0.077 \\
\hline Received food transfer & 0.663 & 0.366 & -0.015 & 0.072 & 0.050 & -0.005 \\
\hline No. of nonfarm income earners & 0.293 & -0.273 & 0.373 & 0.036 & -0.026 & 0.044 \\
\hline Monthly per capita income & $0.009^{* *}$ & $0.009^{* * *}$ & $0.014^{* * *}$ & 0.001 & $0.001^{* * *}$ & $0.001^{* * *}$ \\
\hline Livestock producer & -0.743 & 0.252 & -0.073 & -0.105 & 0.018 & -0.061 \\
\hline Owns dwelling & -0.164 & -0.449 & 0.261 & 0.003 & -0.048 & $0.071^{*}$ \\
\hline Chronically sick HH head & -0.359 & -0.432 & -0.569 & -0.057 & -0.069 & -0.075 \\
\hline Chronically sick spouse & $-0.535^{*}$ & $-0.879^{* *}$ & -0.354 & -0.029 & -0.080 & 0.009 \\
\hline Chronically HH member & -0.392 & -0.075 & -0.102 & $-0.063^{*}$ & -0.019 & -0.021 \\
\hline Indebted & -0.818 & $-0.891^{* *}$ & 1.743 & -0.111 & -0.100 & 0.122 \\
\hline Unemployed $\mathrm{HH}$ head & $-1.568^{* * *}$ & -2.234 & $-1.093^{*}$ & $-0.133^{* * *}$ & -0.416 & -0.093 \\
\hline Unemployed spouse & $-1.474^{*}$ & -1.931 & -0.445 & -0.142 & -0.416 & 0.002 \\
\hline Unemployed HH member & 0.881 & 0.055 & -0.329 & 0.077 & 0.011 & -0.070 \\
\hline Techiman & 0.119 & & & 0.034 & & \\
\hline \multicolumn{7}{|l|}{ Correction terms } \\
\hline IMR1 & 0.123 & 0.223 & -0.170 & 0.011 & 0.025 & -0.019 \\
\hline IMR2 & -0.518 & -0.210 & 0.003 & -0.056 & -0.023 & -0.004 \\
\hline IMR3 & 0.376 & -0.015 & 0.113 & 0.039 & -0.006 & 0.012 \\
\hline Joint F-stat for IMRs & 0.630 & 0.261 & 1.994 & 0.615 & 0.310 & 1.784 \\
\hline P-value of F-test & 0.595 & 0.854 & 0.113 & 0.605 & 0.818 & 0.149 \\
\hline Observations & 2004 & 1008 & 996 & 2004 & 1008 & 996 \\
\hline Log-likelihood value & -4295 & -2148 & -2102 & -1263 & -619.7 & -607.5 \\
\hline Pseudo $R^{2}$ & 0.081 & 0.087 & 0.089 & 0.128 & 0.161 & 0.163 \\
\hline
\end{tabular}

$A M E$ average marginal effect

${ }^{* * *} p<0.01,{ }^{* *} p<0.05,{ }^{*} p<0.1$

Acknowledgements

The authors would like to thank AFSUN for permission to use portions of the AFSUN Household Food Security Baseline Survey instrument for the research. Special thanks to Professors Agnes Andersson Djurfeldt and Magnus Jirström for their useful comments on the initial draft of the manuscript. We thank the two anonymous reviewers and the editor who also provided very useful comments and suggestions that have helped improve the final output. 


\section{Authors' contributions}

HMA conceived the main research question addressed in the article. He also participated in data collection, contributed to data analysis, and produced the initial draft of the manuscript. FMD was a co-principal investigator of the project in Ghana and led the data collection. He developed the analytical framework for the current article and carried out the statistical and econometric analyses and interpretation of results. He also produced the final draft of the manuscript. DBS was a co-principal investigator of the project in Ghana. He provided comments on an initial draft of the paper that led to the development of the initial manuscript. All authors approved the final manuscript.

\section{Funding}

Funding for the Urban Agriculture Project was provided by the Swedish Research Council for Environment, Agricultural Sciences and Spatial Planning. This funding was provided under the Swedish African Urban Agriculture Project.

\section{Availability of data and materials}

The data used for this article is currently not available publicly but could be made available upon request, with permission from the project team leaders.

\section{Competing interests}

The author(s) declare that they have no competing interests.

\section{Author details}

${ }^{1}$ University of Ghana Learning Centres, School of Continuing and Distance Education, University of Ghana, Accra, Ghana. ${ }^{2}$ Institute of Statistical, Social and Economic Research (ISSER), University of Ghana, Accra, Ghana. ${ }^{3}$ Department of Agricultural Economics and Agribusiness, University of Ghana, Accra, Ghana.

\section{Received: 29 July 2018 Accepted: 17 March 2020}

Published online: 31 March 2020

\section{References}

Abu Hatab A, Cavinato MER, Lagerkvist CJ (2019a) Urbanization, livestock systems and food security in developing countries: a systematic review of the literature. Food Security 11(2):279-299

Abu Hatab A, Cavinato MER, Lindemer A, Lagerkvist C-J (2019b) Urban sprawl, food security and agricultural systems in developing countries: a systematic review of the literature. Cities 94:129-142

Armar-Klemesu M (2000) Urban agriculture and food security, nutrition and health. In: Bakker N, Dubbeling M, Gundel S, Sabel-Koschella U, de Zeeuw H (eds) Growing Cities, Growing Food, Urban Agriculture on the Policy Agenda. DSE Feldafing, Feldafing, Germany

Ayerakwa HM (2017) Urban households' engagement in agriculture: implications for household food security in Ghana's medium sized cities. Geographical Research 55(2):217-230

Badami MG, Ramankutty N (2015) Urban agriculture and food security: a critique based on an assessment of urban land constraints. Global Food Security 4:8-15

Bashir, M. K., Schilizzi, S. \& Pandit, R. (2012). The determinants of rural household food security in the Punjab, Pakistan: an econometric analysis. Available:

Battersby J, Watson V (2019) Urban food systems governance and poverty in African cities. Routledge, London \& New York

Becquey E, Martin-Prevel Y, Traissac P, Dembélé B, Bambara A, Delpeuch F (2010) The household food insecurity access scale and an index-member dietary diversity score contribute valid and complementary information on household food insecurity in an urban West-African setting. The Journal of nutrition 140(12):2233-2240

Bryld E (2003) Potentials, problems, and policy implications for urban agriculture in developing countries. Agric Human Values 20(1):79-86

Burchi F, De Muro P (2016) From food availability to nutritional capabilities: advancing food security analysis. Food Policy 60: 10-19

Clinton N, Stuhlmacher M, Miles A, Uludere Aragon N, Wagner M, Georgescu M, Herwig C, Gong P (2018) A global geospatial ecosystem services estimate of urban agriculture. Earth's Future 6(1):40-60

Coates, J., Swindale, A. \& Bilinsky, P. (2007). Household Food Insecurity Access Scale (HFIAS) for measurement of food access: indicator guide. Food and Nutrition Technical Assistance III Project (FANTA). Washington, DC. Available:

Crush J, Frayne B (2011) Supermarket expansion and the informal food economy in Southern African cities: implications for urban food security. J Southern Afr Studies 37(4):781-807

Crush J, Hovorka A, Tevera D (2011) Food security in southern African cities: the place of urban agriculture. Progress Dev Studies 11(4):285-305

Drechsel P, Adam-Bradford A, Raschid-Sally L (2014) Irrigated urban vegetable production in Ghana: a farming system between challenges and resilience. In: Drechsel P, Keraita B (eds) Irrigated urban vegetable production in Ghana: characteristics, benefits and risk mitigation. International Water Management Institute (IWMI), Colombo, Sri Lanka, p 247

Dzanku F, Sarpong D (2010) Agricultural diversification, food self-sufficiency and food security in Ghana-the role of infrastructure and institutions. African Smallholder. Food Crops, Markets and Policy, CABI, Wallingford, UK, pp 189-213

Dzanku FM (2019) Food security in rural sub-Saharan Africa: exploring the nexus between gender, geography and off-farm employment. World Dev 113:26-43

Ellis F, Sumberg J (1998) Food production, urban areas and policy responses. World Dev 26(2):213-225

FAO (2009) Declaration of the World Food Summit on Food Security. Food and Agriculture Organization of the United Nations, Rome

Frayne B, McCordic C, Shilomboleni H (2014) Growing Out of Poverty: Does urban agriculture contribute to household food security in Southern African cities? Urban Forum 25:177-189 
Frelat R, Lopez-Ridaura S, Giller KE, Herrero M, Douxchamps S, Djurfeldt AA, Erenstein O, Henderson B, Kassie M, Paul BK, Rigolot C, Ritzema RS, Rodriguez D, van Asten PJA, van Wijk MT (2016) Drivers of household food availability in subSaharan Africa based on big data from small farms. Proc Natl Acad Sci 113(2):458-463

Gebreyesus SH, Lunde T, Mariam DH, Woldehanna T, Lindtjørn B (2015) Is the adapted Household Food Insecurity Access Scale (HFIAS) developed internationally to measure food insecurity valid in urban and rural households of Ethiopia? BMC Nutrition 1(1):1

Gerstl S, Cissé G, Tanner M (2002) The economic impact of urban agriculture on home gardeners in Ouagadougou. Urban Agric Magazine 7:12-15

Ghana Statistical Service (2014a) 2010 population and housing census: district analytical report: Tamale Metropolis. Ghana Statistical Service, Accra, Ghana

Ghana Statistical Service (2014b) 2010 population and housing census: district analytical report: Techiman Municipality. Ghana Statistical Service, Accra, Ghana

Harou AP, Walker TF, Barrett CB (2016) Is late really better than never? The farmer welfare effects of pineapple adoption in Ghana. Agric Econ:1-12

Headey D, Ecker O (2013) Rethinking the measurement of food security: from first principles to best practice. Food Security 5(3):327-343

Heckman JJ (1979) Sample selection bias as a specification error. Econometrica 47(1):153-161

Korth M, Stewart R, Langer L, Madinga N, Da Silva NR, Zaranyika H, van Rooyen C, de Wet T (2014) What are the impacts of urban agriculture programs on food security in low and middle-income countries: a systematic review. Environ Evidence 3(1):21

Lee-Smith D (2010) Cities feeding people: an update on urban agriculture in equatorial Africa. Environ Urbanization 22(2):483499

Lee-Smith D (2013) Which way for UPA in Africa? City 17(1):69-84

Maxwell D (2001) The importance of urban agriculture to food and nutrition. Annotated biography, ETC-RUAF. CTA publishers, Leusden, Netherlands

Maxwell DG (1995) Alternative food security strategy: a household analysis of urban agriculture in Kampala. World Dev 23(10): $1669-1681$

MoFA (2010). Medium Term Agriculture Sector Investment Plan (METASIP): 2011-2015. Ministry of Food and Agriculture.

Mougeot L (2000) Achieving urban food and nutrition security in developing countries: the hidden significance of urban agriculture. IFPRI, Brief paper 6

Mougeot, L. J. (2005). Agropolis: the social, political, and environmental dimensions of urban agriculture. IDRC

Mougeot LJ (2006) Growing better cities: urban agriculture for sustainable development. IDRC, Ottawa

Nugent R (2000) The impact of urban agriculture on the household and local economies. In: Bakker N, Dubbeling M, Gündel $\mathrm{S}$, Sabel-Koshella U, de Zeeuw H (eds) Growing cities, growing food. Urban agriculture on the policy agenda. Zentralstelle für Ernährung und Landwirtschaft (ZEL), Feldafing, Germany, pp 67-95

Owusu V, Abdulai A, Abdul-Rahman S (2011) Non-farm work and food security among farm households in Northern Ghana. Food Policy 36(2):108-118

Poulsen MN, McNab PR, Clayton ML, Neff RA (2015) A systematic review of urban agriculture and food security impacts in low-income countries. Food Policy 55:131-146

Quisumbing AR, Brown LR, Feldstein HS, Haddad L, Peña C (1996) Women: the key to food security. Food Nutr Bull 17(1):1-2

Rogerson CM (2003) Towards "pro-poor" urban development in South Africa: the case of urban agriculture. Acta Academica 1: 130-158

Rosegrant MW, Cline SA (2003) Global food security: challenges and policies. Science 302(5652):1917-1919

Salarkia N, Abdollahi M, Amini M, Neyestani TR (2014) An adapted Household Food Insecurity Access Scale is a valid tool as a proxy measure of food access for use in urban Iran. Food Security 6(2):275-282

Shifa M, Borel-Saladin J (2019) African urbanisation and poverty. In: Battersby J, Watson V (eds) Urban Food Systems Governance and Poverty in African Cities. Routledge, London \& New York

Smit W (2016) Urban governance and urban food systems in Africa: examining the linkages. Cities 58:80-86

Stewart R, Korth M, Langer L, Rafferty S, Da Silva N, van Rooyen C (2013) What are the impacts of urban agriculture programs on food security in low and middle-income countries? Environ Evidence 2(7):1-13

Tukolske C, Andam KS, Blekking J, Evans T, Caylor K (2018) Measures and determinants of urban food security: evidence from Accra, Ghana. GSSP Working Paper 50. International Food Policy Research Institute, Washington, D.C. Available: http:// ebrary.ifpri.org/cdm/ref/collection/p15738coll2/id/132944

Warren E, Hawkesworth S, Knai C (2015) Investigating the association between urban agriculture and food security, dietary diversity, and nutritional status: a systematic literature review. Food Policy 53:54-66

Weidner T, Yang A, Hamm MW (2019) Consolidating the current knowledge on urban agriculture in productive urban food systems: learnings, gaps and outlook. J Cleaner Production 209:1637-1655

Yamane, T. (1967). Problems to accompany "Statistics, an introductory analysis", 2nd edition. Harper \& Row.

Zezza A, Tasciotti L (2010) Urban agriculture, poverty, and food security: empirical evidence from a sample of developing countries. Food Policy 35(4):265-273

\section{Publisher's Note}

Springer Nature remains neutral with regard to jurisdictional claims in published maps and institutional affiliations. 